\title{
Descriptive Comparisons of the Effect of Apremilast and Methotrexate Monotherapy in Oligoarticular Psoriatic Arthritis: The Corrona Psoriatic Arthritis/Spondyloarthritis Registry Results
}

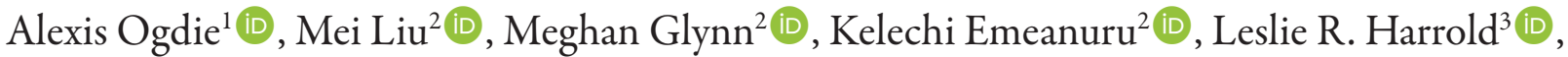 \\ Sven Richter ${ }^{4}$, Benoit Guerette ${ }^{4}$, and Philip J. Mease ${ }^{5}$
}

\begin{abstract}
Objective. Therapeutic response was evaluated among new apremilast, methotrexate (MTX), or biologic disease-modifying antirheumatic drug (bDMARD) initiators with oligoarticular psoriatic arthritis (PsA).

Methods. Patients with oligoarticular PsA in the Corrona PsA/Spondyloarthritis Registry initiating treatment with apremilast, MTX, or bDMARD, and completing 6-month follow-up were included.

Results. In total, 150 patients initiated monotherapy (apremilast: $n=34$; MTX: $n=15$; bDMARD: $\mathrm{n}=101$ ). Apremilast initiators had higher baseline disease activity than MTX initiators. At follow-up, apremilast initiators experienced numerically greater disease activity improvements than MTX initiators and similar improvements to bDMARD initiators.

Conclusion. Findings suggest apremilast monotherapy is an effective option for patients with oligoarticular PsA.
\end{abstract}

Key Indexing Terms: arthritis, methotrexate, psoriatic arthritis, TNF receptors

Oligoarticular psoriatic arthritis (PsA), defined as $<5$ involved joints ${ }^{1,2}$, affects $\approx 50 \%$ of patients with PsA ${ }^{3}$. Typical randomized controlled trials have not focused on this population, and on average, patients enrolled have swollen and tender joint counts of 12 and 21, respectively ${ }^{4}$. Despite the high prevalence of oligoarticular PsA, data are lacking in this population, and recommendations for management remain largely unaddressed ${ }^{45,6}$.

Our study assessed baseline clinical characteristics of patients with oligoarticular PsA ( $\leq 4$ swollen joints) to determine the effect of apremilast or methotrexate (MTX) treatment on disease activity. Patients initiating biologic disease-modifying antirheumatic drug (bDMARD) monotherapy were examined as a point of reference.

\section{MATERIALS AND METHODS}

Study design. A cohort study was performed in the Corrona Psoriatic Arthritis/Spondyloarthritis (PsA/SpA) Registry, a multicenter registry that recruited patients among $>50$ participating rheumatologists in the United States ${ }^{7}$. Adults (aged $\geq 18 \mathrm{yrs}$ ) were included if they had PsA and
This study was sponsored by Corrona, $L L C$, and the analysis was funded by Celgene Corporation. Amgen acquired the worldwide rights to Otezla (apremilast) on November 21, 2019. Access to study data was limited to Corrona, and Corrona statisticians completed all of the analysis.

${ }^{1}$ A. Ogdie, MD, Departments of Medicine and Epidemiology, Perelman School of Medicine, University of Pennsylvania, Philadelphia, Pennsylvania; ${ }^{2}$ M. Liu, PhD, M. Glynn, MS, K. Emeanuru, MPH, Corrona, LLC, Waltham; ${ }^{3}$ L.R. Harrold, MD, MPH, Corrona, LLC, Waltham, and Department of Medicine, University of Massachusetts Medical School, Worcester, Massachusetts; ${ }^{4}$ S. Richter, MD, B. Guerette, PhD, Global Medical Affairs, Amgen Inc., Thousand Oaks, California; ${ }^{5}$ P.J. Mease, MD, Division of Rheumatology Clinical Research, Swedish Medical Center/Providence St. Joseph Health, and Division of Rheumatology, University of Washington School of Medicine, Seattle, Washington, USA.

All authors contributed to the interpretation of the results.

$A O$ has received grant/research support from Pfizer Inc. and Novartis and has served as a consultant to AbbVie, Amgen, Bristol Myers Squibb, Celgene Corporation, Corrona, Eli Lilly and Company, Novartis, Pfizer Inc., and Takeda. ML, MG, and KE have worked on Corrona-contracted subscriptions for AbbVie, Amgen, Bristol Myers Squibb, Boebringer Ingelheim, Celgene Corporation, Crescendo, Eli Lilly and Company, Genentech, Gilead, GSK,
Janssen, Momenta Pharmaceuticals, Novartis, Pfizer Inc., Regeneron, Roche, Merck, UCB, and Valeant. LRH is an employee and shareholder of Corrona, $L L C$, received grants from Pfizer Inc., and has served as a consultant to AbbVie, Bristol Myers Squibb and Roche. SR and BG are employees of Amgen Inc. and were employees of Celgene Corporation at the time of study conduct. $P J M$ has received grant/research support from and served as a consultant for Abbott, Amgen, Biogen Idec, Bristol Myers Squibb, Celgene Corporation, Eli Lilly and Company, Genentech, Janssen, Novartis, Pfizer Inc., Roche, and $U C B$, and has served on the speakers bureau for Abbott, Amgen, Biogen Idec, Bristol Myers Squibb, Eli Lilly and Company, Genentech, Janssen, Pfizer Inc., and UCB. Corrona has been supported through contracted subscriptions in the last 2 years by AbbVie, Amgen, Boehringer Ingelheim, Bristol Myers Squibb, Celgene Corporation, Crescendo, Eli Lilly and Company, Genentech, Gilead, GSK, Janssen, Merck, Momenta Pharmaceuticals, Novartis, Ortho Dermatologics, Pfizer Inc., Regeneron, Roche, Sanofi, Sun, and UCB.

Address correspondence to Dr. A. Ogdie, 3400 Spruce Street, 5 White Building, Hospital of the University of Pennsylvania, Philadelphia, PA 19104, USA. Email:alogdie@pennmedicine.upenn.edu. Full Release Article. For details see Reprints and Permissions at jrheum.org. Accepted for publication October 23, 2020. 
oligoarthritis (defined as $\leq 4$ swollen joints); were enrolled in the Corrona PsA/SpA Registry; initiated apremilast, MTX, or bDMARD monotherapy as the first initiation within the registry between June 1, 2014, and March 1, 2018; and had a 6-month follow-up visit with a time window of 3 to 9 months within the same period. Patients were defined as having polyarticular or oligoarticular PsA at the time of therapy initiation. Patients defined as having oligoarticular PsA may have had polyarticular disease previously, as they may have had changing numbers of joints involved with therapy selection based on patient characteristics.

Outcomes. Outcomes at 6 months included assessments of disease activity and patient-reported outcome (PRO) measures. Included were the proportion of patients with $>1$ swollen joint or $>1$ tender joint at baseline achieving a swollen joint count (SJC) of 0 or 1 or a tender joint count (TJC) of 0 or 1, respectively; change from baseline in SJC and TJC; and change from baseline in the Clinical Disease Activity Index for Psoriatic Arthritis (cDAPSA) score and the cDAPSA core components.

The cDAPSA score was calculated as SJC (0-66) plus TJC (0-68) plus the patient global assessment of disease activity-arthritis and psoriasis (PtGA-PsO) visual analog scale (VAS) score $(0-10 \mathrm{~cm})$ plus the overall pain VAS $(0-10 \mathrm{~cm})$ score. Additional PRO measures included the change from baseline in fatigue VAS $(0-100 \mathrm{~mm})$ score, proportion of patients achieving the minimal clinically important difference (MCID; $\geq 0.35$-point decrease) in the Health Assessment Questionnaire-Disability Index (HAQ-DI) score, change from baseline in PtGA-arthritis (PtGA-PsA) VAS score $(0-100 \mathrm{~mm})$, and the proportion of patients without physician-reported clinical characteristics of nail psoriasis at 6 months.

Statistical analysis. Descriptive statistics were calculated for patient demographic, clinical, and treatment characteristics at the index visit and outcomes at the 6-month follow-up visit. The index visit was defined as the visit in which patients reported treatment initiation with apremilast, MTX, or bDMARD. All data were analyzed descriptively using means and SD for continuous variables and presented as counts and percentages of patients for categorical variables.

Ethical conduct. All participating investigators were required to obtain full board approval for conducting research involving human subjects. Sponsor approval and continuing review was obtained through a central investigational review board (New England Independent Review Board, NEIRB No. 120160610); there were > 50 study sites. For academic investigative sites that did not receive a waiver to use the central investigational review board, full board approval was obtained from the respective governing investigational review boards and documentation of approval was submitted to the sponsor before initiating any study procedures. All registry patients were required to provide written informed consent before participating.

\section{RESULTS}

Index visit: patient demographics and clinical characteristics. A total of 1593 patients with oligoarticular PsA were listed in the Corrona PsA/SpA Registry between June 2014 and March 2018. Of these patients, 150 had initiated monotherapy with apremilast $(\mathrm{n}=34)$, MTX $(\mathrm{n}=15)$, or bDMARD $(\mathrm{n}=101)$ as the first initiation during follow-up for oligoarticular PsA (Supplementary Figure 1, available with the online version of this article). Patient demographic, clinical, and treatment characteristics at the index visit are presented in Table 1. Patients who initiated MTX monotherapy were slightly older and a higher proportion were female compared with patients in the apremilast and bDMARD monotherapy groups. More than half of patients in all 3 monotherapy groups were obese. Mean disease duration was generally similar among monotherapy groups.

Overall, treatment and clinical characteristics of apremilast initiators were suggestive of more refractory oligoarticular PsA compared with MTX initiators (Table 1). Among apremilast and MTX initiators, $79 \%$ and $20 \%$ received $\geq 1$ prior bDMARD, respectively. Patients who initiated apremilast had higher levels of disease activity at baseline, measured by a cDAPSA score $>13$ (moderate or high disease activity), and fewer had minimal disease activity (MDA) at baseline compared with patients who initiated MTX or bDMARD. Patients initiating apremilast monotherapy also reported numerically higher mean scores of PRO measures at baseline, including PtGA-PsA and fatigue VAS scores; likewise, the proportion of patients with a HAQ-DI score $>0.5$ was also higher with apremilast monotherapy.

Disease activity assessments. A numerically greater proportion of patients with an SJC $>1$ or TJC $>1$ at baseline who received apremilast monotherapy achieved an SJC $\leq 1$ or TJC $\leq 1$ at 6 months than those who received monotherapy with MTX or bDMARD (Figure 1). Achievement of an SJC $\leq 1$ or TJC $\leq 1$ in the apremilast monotherapy group was more similar to the bDMARD monotherapy group than to the MTX monotherapy group (Figure 1). Mean changes in SJC and TJC, respectively, from baseline were numerically greater with apremilast monotherapy $(-0.4$ and -0.4$)$ compared with MTX $(0.1$ and -0.3$)$ or bDMARD (0.2 and -0.1) monotherapy. A numerically greater proportion of apremilast monotherapy initiators who were in a moderate or high disease activity cDAPSA category at baseline achieved low disease activity (LDA) or remission (REM) at 6 months compared with MTX and bDMARD monotherapy initiators (Figure 2). Achievement of LDA or REM in the apremilast monotherapy initiators was more comparable to bDMARD monotherapy initiators than to MTX monotherapy initiators (Figure 2). Of those patients who did not have MDA at initiation, $8.7 \%(2 / 23)$ in the apremilast monotherapy group, $0 \%$ $(0 / 7)$ in the MTX group, and $17.9 \%(10 / 56)$ in the bDMARD monotherapy group achieved MDA at the 6-month visit. None of the patients receiving apremilast monotherapy or MTX who did not have very LDA (VLDA) at initiation achieved VLDA at the 6-month visit; $4.8 \%(4 / 84)$ initiating bDMARD monotherapy achieved VLDA. The mean improvement from baseline in cDAPSA score was numerically greater in patients receiving apremilast monotherapy $(-1.5)$ compared with those receiving $\operatorname{MTX}(-0.2)$ or bDMARD $(-0.1)$ monotherapy.

PRO measures. At 6 months, patients in all 3 monotherapy groups experienced minimal changes from baseline in mean PtGA-PsA VAS, overall pain VAS, fatigue VAS, and PtGA-PsO VAS scores. Changes from baseline in the apremilast, MTX, and bDMARD monotherapy groups were $-0.2,2.5$, and 0.4 for mean PtGA-PsA VAS scores; $0.2,-0.1$, and 0.1 for overall pain VAS scores; $-1.4,0.3$, and -0.3 for mean fatigue VAS scores; and $-2.3,1.7$, and -2.0 for PtGA-PsO VAS scores, respectively. The proportions of patients achieving at least a 0.35 -point improvement in HAQ-DI MCID were similar in the apremilast, MTX, and bDMARD monotherapy groups (Supplementary Figure 2, available with the online version of this article). A numerically greater proportion of patients with physician-reported nail psoriasis at baseline were without physician-reported nail psoriasis at 


\begin{tabular}{|c|c|c|c|}
\hline & $\begin{array}{l}\text { Apremilast, } \\
\mathrm{n}=34\end{array}$ & $\begin{array}{l}\text { MTX, } \\
\mathrm{n}=15\end{array}$ & $\begin{array}{l}\text { bDMARD, } \\
\mathrm{n}=101\end{array}$ \\
\hline Age, yrs & $55.7(12.6), \mathrm{n}=33$ & $61.5(16.6), n=15$ & $52.9(11.5), \mathrm{n}=99$ \\
\hline Female, n (\%) & $20(58.8), \mathrm{n}=34$ & $10(71.4), \mathrm{n}=14$ & $59(59.0), \mathrm{n}=100$ \\
\hline BMI, $\mathrm{kg} / \mathrm{m}^{2}$ & $34.4(9.3), \mathrm{n}=34$ & $30.6(8.1), \mathrm{n}=14$ & $32.7(6.8), \mathrm{n}=96$ \\
\hline Obese $^{\mathrm{a}}, \mathrm{n}(\%)$ & $22(64.7), n=34$ & $8(57.1), \mathrm{n}=14$ & $58(60.4), \mathrm{n}=96$ \\
\hline Duration since PsA diagnosis, yrs & $8.0(6.7), n=33$ & $5.4(7.8), \mathrm{n}=14$ & $9.7(9.4), \mathrm{n}=96$ \\
\hline Prior non-bDMARD use, n (\%) & $23(67.6), n=34$ & $2(13.3), n=15$ & $73(72.3), \mathrm{n}=101$ \\
\hline Prior biologic use $(\geq 1), \mathrm{n}(\%)$ & $27(79.4), n=34$ & $3(20.0), n=15$ & $76(75.2), \mathrm{n}=101$ \\
\hline $\operatorname{SJC}^{\mathrm{b}}(0-66)$ & $1.5(1.5), \mathrm{n}=34$ & $1.0(1.1), \mathrm{n}=15$ & $0.8(1.3), \mathrm{n}=101$ \\
\hline $\mathrm{SJC}>1, \mathrm{n}(\%)$ & $17(50.0), \mathrm{n}=34$ & $4(26.7), n=15$ & $26(25.7), \mathrm{n}=101$ \\
\hline TJC (0-68) & $2.7(3.9), \mathrm{n}=34$ & $2.5(3.3), \mathrm{n}=15$ & $3.1(5.9), \mathrm{n}=101$ \\
\hline $\mathrm{TJC}>1, \mathrm{n}(\%)$ & $17(50.0), \mathrm{n}=34$ & $8(53.3), \mathrm{n}=15$ & $39(38.6), \mathrm{n}=101$ \\
\hline SPARCC enthesitis > 0, n (\%) & $6.0(17.6)$ & $2.0(13.3)$ & $20(19.8)$ \\
\hline Dactylitis count $>0, \mathrm{n}(\%)$ & $6.0(17.6)$ & $2.0(13.3)$ & $6.0(5.9)$ \\
\hline Axial disease, $\mathrm{n}(\%)$ & $6(17.6)$ & $3(20.0)$ & $22(21.8)$ \\
\hline MDA, n (\%) & $6(20.0), n=30$ & $4(36.4), n=11$ & $35(37.2), \mathrm{n}=94$ \\
\hline VLDA, n (\%) & $3(10.0), \mathrm{n}=30$ & $1(9.1), \mathrm{n}=11$ & $7(7.4), n=94$ \\
\hline cDAPSA score $(0-154)$ & $14.0(8.5), \mathrm{n}=34$ & $11.5(4.9), \mathrm{n}=11$ & $12.3(9.1), \mathrm{n}=98$ \\
\hline \multicolumn{4}{|l|}{ cDAPSA category, n (\%) } \\
\hline Remission $(\leq 4)$ & $5(14.7), n=34$ & $1(9.1), \mathrm{n}=11$ & $17(17.3), \mathrm{n}=98$ \\
\hline Low disease activity ( $>4$ to $\leq 13$ ) & $12(35.3), \mathrm{n}=34$ & $7(63.6), n=11$ & $45(45.9), \mathrm{n}=98$ \\
\hline Moderate disease activity $(>13$ to $\leq 27)$ & $14(41.2), \mathrm{n}=34$ & $3(27.3), \mathrm{n}=11$ & $30(30.6), \mathrm{n}=98$ \\
\hline High disease activity $(>27)$ & $3(8.8), n=34$ & $0(0.0), \mathrm{n}=11$ & $6(6.1), \mathrm{n}=98$ \\
\hline PtGA-PsA VAS score $(0-100 \mathrm{~mm})$ & $47.1(29.8), \mathrm{n}=34$ & $32.5(26.3), \mathrm{n}=13$ & $42.9(27.7), \mathrm{n}=99$ \\
\hline $\begin{array}{l}\text { Patient-reported overall pain VAS score } \\
\quad(0-100 \mathrm{~mm})\end{array}$ & $50.5(31.1), \mathrm{n}=34$ & $46.7(26.5), \mathrm{n}=14$ & $42.7(29.6), \mathrm{n}=99$ \\
\hline $\begin{array}{l}\text { Patient-reported fatigue VAS score } \\
(0-100 \mathrm{~mm})\end{array}$ & $55.9(30.0), \mathrm{n}=34$ & $37.8(31.9), \mathrm{n}=15$ & $41.2(29.0), \mathrm{n}=101$ \\
\hline HAQ-DI score & $1.0(0.7), \mathrm{n}=34$ & $0.5(0.4), \mathrm{n}=14$ & $0.7(0.6), \mathrm{n}=100$ \\
\hline HAQ-DI score > 0.5, n (\%) & $21(61.8), n=34$ & $6(42.9), \mathrm{n}=14$ & $45(45.0), \mathrm{n}=100$ \\
\hline Psoriasis-affected BSA, \% & $7.1(17.6), \mathrm{n}=30$ & $4.8(9.4), n=14$ & $4.1(7.8), \mathrm{n}=97$ \\
\hline PtGA-PsO VAS score $(0-100 \mathrm{~mm})$ & $47.1(29.4), \mathrm{n}=34$ & $28.4(16.6), n=12$ & $41.2(26.8), \mathrm{n}=99$ \\
\hline $\begin{array}{l}\text { Presence of physician-reported nail } \\
\text { psoriasis, } \mathrm{n}(\%)\end{array}$ & $8(23.5), \mathrm{n}=34$ & $3(20.0), \mathrm{n}=15$ & $25(24.8), \mathrm{n}=101$ \\
\hline
\end{tabular}

Values are expressed as mean (SD) unless otherwise indicated. ${ }^{a}$ BMI $\geq 30 \mathrm{~kg} / \mathrm{m}^{2}$. ${ }^{\mathrm{b}}$ Patients had oligoarticular PsA, defined as $\leq 4$ swollen joints. bDMARD: biologic disease-modifying antirheumatic drug; BSA: body surface area; cDAPSA: Clinical Disease Activity Index for Psoriatic Arthritis; HAQ-DI: Health Assessment Questionnaire-Disability Index; MDA: minimal disease activity; MTX: methotrexate; PtGA-PsA: patient global assessment of disease activity-arthritis; PtGA-PsO: patient global assessment of disease activity-arthritis and psoriasis; PsA: psoriatic arthritis; SJC: swollen joint count; SPARCC: Spondyloarthritis Research Consortium of Canada; TJC: tender joint count; VAS: visual analog scale; VLDA: very low disease activity.

6 months in the apremilast monotherapy group compared with the MTX and bDMARD monotherapy groups (Supplementary Figure 3). Improvement in nail psoriasis in the apremilast monotherapy group was more similar to the bDMARD monotherapy group than to the MTX monotherapy group (Supplementary Figure 3).

\section{DISCUSSION}

Although oligoarticular PsA, by definition, involves fewer joints than polyarticular PsA, the 2 subgroups had comparable disease

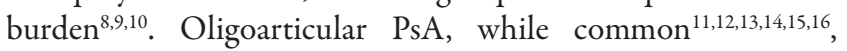
remains understudied and identification of effective management of this PsA phenotype is warranted. Despite use in a more often treatment-refractory patient population, the apremilast monotherapy group experienced improvements in disease activity and PRO measures; improvements were also experienced in the MTX group. The improvements observed with apremilast monotherapy in this population were comparable with bDMARD monotherapy. Our comparison of the 3 groups was descriptive, without statistical testing, because we cannot fully address confounding by indication when comparing different therapy classes across different lines of therapy. Of note, in many cases, patients included in this study were receiving apremilast shortly after its approval. As is generally observed, due to physician comfort with a new medication and payer preference, new-to-market therapies are often used in a more recalcitrant patient population. Over time, apremilast has been more commonly used earlier in the disease course ${ }^{17}$. 
A

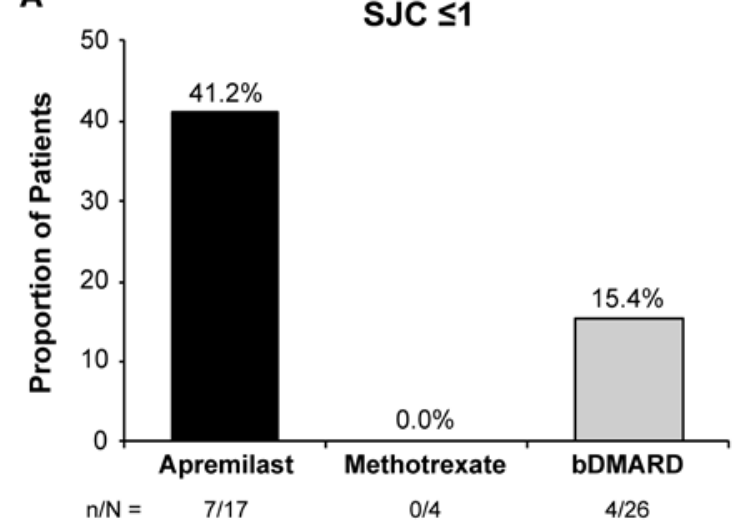

B

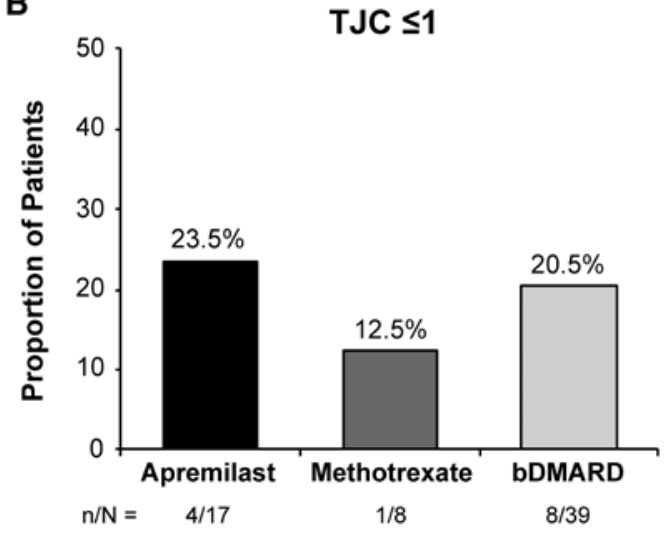

Figure 1. The proportions of patients with $>1$ swollen joint or $>1$ tender joint at baseline achieving (A) swollen joint count (SJC) $\leq 1$ and (B) tender joint count (TJC) $\leq 1$ at 6 months. bDMARD: biologic disease-modifying antirheumatic drug; $\mathrm{n} / \mathrm{N}$ : number of responders/patients with sufficient data for evaluation.

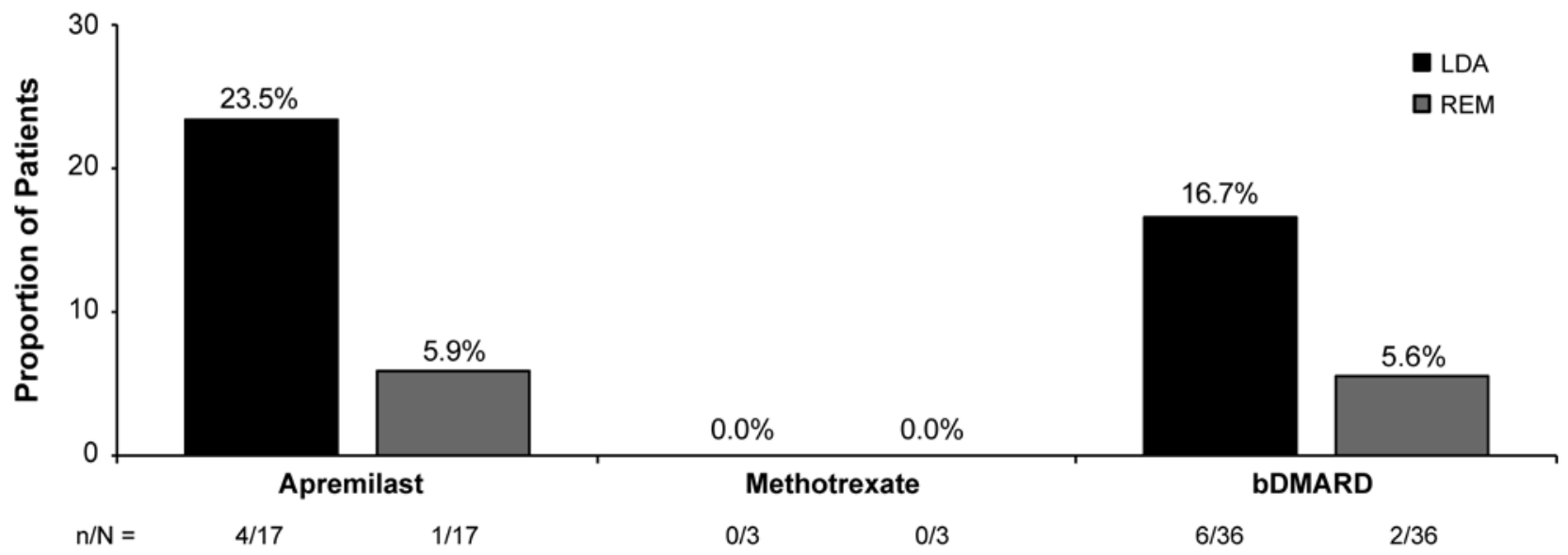

Figure 2. Achievement of low disease activity (LDA)/remission (REM). Proportions of patients in moderate or high Clinical Disease Activity Index for Psoriatic Arthritis (cDAPSA) categories at baseline achieving cDAPSA LDA or REM categories at 6 months. bDMARD: biologic disease-modifying antirheumatic drug; $\mathrm{n} / \mathrm{N}$ : number of responders/patients with sufficient data for evaluation.

A limitation of this study is the small sample size and therefore statistical testing was not performed. Further, only patients who completed the 6-month follow-up visit were analyzed, which can introduce selection bias. A larger phase IV, multicenter, randomized, double-blind, placebo-controlled, parallel-group study (ClinicalTrials.gov: NCT03747939) is currently assessing the efficacy of apremilast in patients with early oligoarticular PsA despite initial stable treatment with either nonsteroidal antiinflammatory drugs and/or 1 conventional synthetic DMARD. Overall, findings from this exploratory analysis suggest that apremilast monotherapy is an effective treatment option for oligoarticular PsA.

\section{ACKNOWLEDGMENT}

Writing support was funded by Celgene Corporation and provided by Kristin Carlin, RPh, MBA, of Peloton Advantage, LLC, an OPEN Health company. The authors, however, directed and are fully responsible for all content and editorial decisions for this report.

\section{DATA SHARING}

The Corrona dataset is based on a large US multicenter study adhering to a number of institutional review boards, with complex logistics. Patients did not provide consent to raw data sharing during the data collection for this purpose, and the Corrona data sharing policies do not permit raw data sharing for this purpose. An aggregated limited dataset from the current analyses is available to qualified investigators with an approved protocol. Data requests may be sent to Corrona, represented by Dr. Jeffrey Greenberg; email: jgreenberg@corrona.org.

\section{ONLINE SUPPLEMENT}

Supplementary material accompanies the online version of this article.

\section{REFERENCES}

1. Marchesoni A. Oligoarticular psoriatic arthritis: addressing clinical challenges in an intriguing phenotype. Rheumatol Ther 2018; 5:311-6.

2. Ritchlin CT, Colbert RA, Gladman DD. Psoriatic arthritis. N Engl J Med 2017;376:957-70. 
3. Ogdie A, Weiss P. The epidemiology of psoriatic arthritis. Rheum Dis Clin North Am 2015;41:545-68.

4. Ogdie A, Coates L. The changing face of clinical trials in psoriatic arthritis. Curr Rheumatol Rep 2017;19:21.

5. Gossec L, Smolen JS, Ramiro S, De Wit M, Cutolo M, Dougados $\mathrm{M}$, et al. European League Against Rheumatism (EULAR) recommendations for the management of psoriatic arthritis with pharmacological therapies: 2015 update. Ann Rheum Dis 2016;75:499-510.

6. Coates LC, Kavanaugh A, Mease PJ, Soriano ER, Acosta-Felquer ML, Armstrong AW, et al. Group for Research and Assessment of Psoriasis and Psoriatic Arthritis: treatment recommendations for psoriatic arthritis 2015. Arthritis Rheumatol 2016;68:1060-71.

7. Mease PJ, Karki C, Palmer JB, Etzel CJ, Kavanaugh A, Ritchlin $\mathrm{CT}$, et al. Clinical and patient-reported outcomes in patients with psoriatic arthritis (PsA) by body surface area affected by psoriasis: results from the Corrona PsA/Spondyloarthritis Registry. J Rheumatol 2017;44:1151-8.

8. Ogdie A, Liu M, Glynn M, Emeanuru K, Harrold L, Richter R, et al. SAT0343. Burden of disease at treatment initiation among biologic-naive patients with oligoarticular versus polyarticular psoriatic arthritis in the Corrona Psoriatic Arthritis/ Spondyloarthritis Registry [abstract]. Ann Rheum Dis 2019;78:1251.

9. Wervers K, Luime JJ, Tchetverikov I, Gerards AH, Kok MR, Appels CWY, et al. Influence of disease manifestations on health-related quality of life in early psoriatic arthritis. J Rheumatol 2018; 45:1526-31.

10. Huscher D, Albrecht K, Bischoff S, Thiele K, Behrens F, Fischer $\mathrm{K}$, et al. Patients with psoriatic arthritis and oligoarthritic subtype report higher disease burden than patients with a polyarthritic pattern - data from the German Collaborative Arthritis Centres [abstract]. Arthritis Rheumatol 2015;67 Suppl 10.

11. Michet CJ, Mason TG, Mazlumzadeh M. Hip joint disease in psoriatic arthritis: risk factors and natural history. Ann Rheum Dis 2005;64:1068-70.

12. Queiro R, Canete JD, Montilla C, Abad M, Montoro M, Gomez S, et al; MAAPS study group. Minimal disease activity and impact of disease in psoriatic arthritis: a Spanish cross-sectional multicenter study. Arthritis Res Ther 2017;19:72.

13. Wilson FC, Icen M, Crowson CS, McEvoy MT, Gabriel SE, Kremers HM. Incidence and clinical predictors of psoriatic arthritis in patients with psoriasis: a population-based study. Arthritis Rheum 2009;61:233-9.

14. Nossent JC, Gran JT. Epidemiological and clinical characteristics of psoriatic arthritis in northern Norway. Scand J Rheumatol 2009;38:251-5.

15. Lindqvist UR, Alenius GM, Husmark T, Theander E, Holmstrom G, Larsson PT; Psoriatic Arthritis Group of the Society for Rheumatology. The Swedish early psoriatic arthritis register--2-year followup: a comparison with early rheumatoid arthritis. J Rheumatol 2008;35:668-73.

16. Gladman DD, Shuckett R, Russell ML, Thorne JC, Schachter RK. Psoriatic arthritis (PsA)--an analysis of 220 patients. QJ Med 1987;62:127-41.

17. Ogdie A, Liu M, Glynn M, Emeanuru K, Harrold LR, Mohawk $\mathrm{J}$, et al., editors. Burden of disease in patients initiating apremilast treatment: 2014-2019 findings from the Corrona Psoriatic Arthritis/Spondyloarthritis Registry. Poster presented at: 2020 European E-Congress of Rheumatology; June, 2020; Geneva, Switzerland. 